\title{
Thermo-mechanical Behaviour of 23/8 Austenitic Stainless Steel
}

\author{
Nilamadhaba SAHU, ${ }^{1)}$ Ashish SELOKAR ${ }^{2)}$ and Ujjwal PRAKASH ${ }^{3) *}$ \\ Department of Metallurgical and Materials Engineering, Indian Institute of Technology Roorkee, Roorkee-247667 India.
}

(Received on October 1, 2013; accepted on December 27, 2013)

\begin{abstract}
The flow behaviour as well as initiation of dynamic recrystallization in Fe-23wt\%Cr-8wt\%Ni (23/8 steel) austenitic steel containing 0.28 wt\% nitrogen was investigated using Gleeble 3800 thermomechanical simulator. Hot working was carried out in temperature range of $950-1100^{\circ} \mathrm{C}$ at strain rates ranging from 0.01 to $10 \mathrm{~s}^{-1}$. Based on experimental results a constitutive equation was predicted for peak flow stress embracing the Zener-Hollomon parameter. The deformation activation energy and stress exponent were calculated as $671.66 \mathrm{KJ} / \mathrm{mole}$ and 3.762 respectively. The critical stress for initiation of dynamic recrystallization was determined by the identification of an inflection point in the strain hardening rate versus stress plot. The average normalized critical stress for the metal was found as 0.806 . The power dissipation efficiency and instability maps for the 23/8 austenitic stainless steel were developed adopting modified Dynamic material model (DMM). The power dissipation efficiency calculated using DMM was compared with that of modified DMM. The validity of power law during deformation process for the above material was analysed. The processing maps in connection with microstructures and experimental flow curves were used to interpret possible safe processing conditions of the above material during hot metal working. The peak efficiency of $35.91 \%$ at 0.6 strain was observed under $1100^{\circ} \mathrm{C}$ and $1 \mathrm{~s}^{-1}$ whereas the optimum processing condition was found under $1100^{\circ} \mathrm{C}$ and $0.1 \mathrm{~s}^{-1}$ having efficiency of $23.4 \%$. Dominating damage mechanisms causing microstructure instability in this material are identified.
\end{abstract}

KEY WORDS: constitutive equation; critical stress; $23 / 8$ austenitic steel; thermomechanical processing; dynamic recrystallization; processing maps.

\section{Introduction}

Nitrogen containing austenitic steel exhibits an excellent combination of erosion and corrosion resistance. ${ }^{1)} \mathrm{Fe}-23 \mathrm{Cr}-$ $8 \mathrm{Ni}$ steel containing $0.28 \mathrm{wt} \%$ nitrogen is an austenitic stainless steel (23/8 steel) and its mechanical properties can be enhanced by careful thermomechanical processing. Material flow during deformation process is related to flow stress of the material which can be expressed mathematically as a function of processing parameters.

Hot workability of metals is concerned with the extent of plastic deformation having defect free microstructure during a specific high temperature metal working process. ${ }^{2}$ Incidence of defective microstructures during high temperature mechanical processing increases the rate of rejection in the finished parts. A safe window of optimum processing parameters is required during hot working of the metal to avoid defects and flow instability in the microstructures. ${ }^{3)}$ For this processing maps are becoming more popular for predicting the optimum processing parameters during hot deformation process. ${ }^{4)}$

The present research aims to identify critical stress for initiation of dynamic recrystallization (DRX), to establish a mathematical model for flow behaviour and to investigate the workability of $23 / 8$ austenitic stainless steel during hot

\footnotetext{
* Corresponding author: E-mail: uprakash2@rediffmail.com DOI: http://dx.doi.org/10.2355/isijinternational.54.970
}

deformation. The power dissipation efficiency and instability maps are developed adopting modified Dynamic material model (DMM). This is correlated with the observed microstructure.

\section{Experimental Procedure}

Plates of 23/8 austenitic stainless steel measuring $110 \mathrm{~mm} \times$ $90 \mathrm{~mm} \times 20 \mathrm{~mm}$ were received from M/S Star Wire (India) Ltd., Ballabhgarh (Haryana). Chemical composition of the material is given in Table 1.

Cylindrical specimens of $10 \mathrm{~mm}$ diameter and $15 \mathrm{~mm}$ height were machined from the received plates for uniaxial hot compression testing in a Gleeble-3800 thermomechanical simulator. The specimens were deformed at temperatures of $950^{\circ} \mathrm{C}, 1000^{\circ} \mathrm{C}, 1050^{\circ} \mathrm{C}$, and $1100^{\circ} \mathrm{C}$ and strain rates of $0.01,0.1,1$, and $10 \mathrm{~s}^{-1}$. The heating rate and cooling rate of each specimen was maintained by a thermocouple feedback controlled AC current. All the samples were heated to $1100^{\circ} \mathrm{C}$ following heating rate of $10^{\circ} \mathrm{C} / \mathrm{s}$ and soaked for 300 seconds at that temperature and then cooled to deformation temperature at $5^{\circ} \mathrm{C} / \mathrm{s}$. The samples were then held for 300

Table 1. Chemical composition of $23 / 8$ austenitic stainless steel.

\begin{tabular}{|c|c|c|c|c|c|c|c|c|c|}
\hline Material & $\mathrm{C}$ & $\mathrm{Si}$ & $\mathrm{Mn}$ & $\mathrm{Cr}$ & $\mathrm{Ni}$ & $\mathrm{N}$ & $\mathrm{S} \mathrm{Cu}$ Co P & Mo & $\mathrm{Fe}$ \\
\hline $23 / 8$ steel & 0.31 & 0.765 & 2.05 & 22.48 & 7.45 & 0.28 & In traces. & 0.12 & Bal \\
\hline
\end{tabular}


seconds at deformation temperature and subsequently reduced to $50 \%$ of the original size which is equivalent to 0.69 true strains at the end of the test. Tantalum foils were used between anvil and the specimen in order to reduce barreling due to friction. Specimens were water quenched immediately after deformation to record the high temperature deformed microstructures.

Deformed specimens were cut parallel to compression axis at the centre. The cut surfaces were mechanically ground and polished to $0.5 \mu \mathrm{m}$ grade alumina powder finish. The polished surfaces were etched with glyceregia $(5 \mathrm{ml}$ $\mathrm{HNO}_{3}+15 \mathrm{ml} \mathrm{HCl}+10 \mathrm{ml}$ glycerol). Sample microstructure was recorded using a Leica DMI 5000M optical microscope.

\section{Result and Discussion}

\subsection{Flow Curves}

The flow behaviour of $23 / 8$ steel at different deformation temperatures obtained during hot deformation process is shown in Figs. 1(a) to 1(d). All the curves exhibit a peak stress. The curves can be summarized as follows:

(a) Flow stress softening with Steady stress state attainment after the peak stress achievement. Flow curves of $950^{\circ} \mathrm{C}$ with $0.01 \mathrm{~s}^{-1}, 1000^{\circ} \mathrm{C}$ with $0.01 \mathrm{~s}^{-1}, 1050^{\circ} \mathrm{C}$ with $0.01 \mathrm{~s}^{-1}$ and 0.1 $\mathrm{s}^{-1}$ and $1100^{\circ} \mathrm{C}$ with $0.01 \mathrm{~s}^{-1}$ strain rates fall in this category.

(b) Continuous flow stress softening with no steady stress attainment after the peak stress achievement. Flow curves of $950^{\circ} \mathrm{C}$ with $10 \mathrm{~s}^{-1}, 1 \mathrm{~s}^{-1}$ and $0.1 \mathrm{~s}^{-1}, 1000^{\circ} \mathrm{C}$ with $1 \mathrm{~s}^{-1}$, and $0.1 \mathrm{~s}^{-1}, 1050^{\circ} \mathrm{C}$ with $1 \mathrm{~s}^{-1}, 1100^{\circ} \mathrm{C}$ with $10 \mathrm{~s}^{-1}$ and $1100^{\circ} \mathrm{C}$ with $1 \mathrm{~s}^{-1}$ strain rates come under this type.

(c) No flow softening i.e. steady state attainments with the flat nature of the flow stress curve after the peak stress achievement. Flow curves of $1000^{\circ} \mathrm{C}$ with $10 \mathrm{~s}^{-1}, 1050^{\circ} \mathrm{C}$ with $10 \mathrm{~s}^{-1}$ come under this type.

(d) Presence of flow stress softening characteristics in type (a) and (b) type of flow curves after Peak stress is an indication of occurrence of DRX. ${ }^{5}$

\subsection{Initiation of DRX and Determination of Critical Stress}

According to Poliak and Jonas ${ }^{6)}$ strain hardening rate $(\theta=$
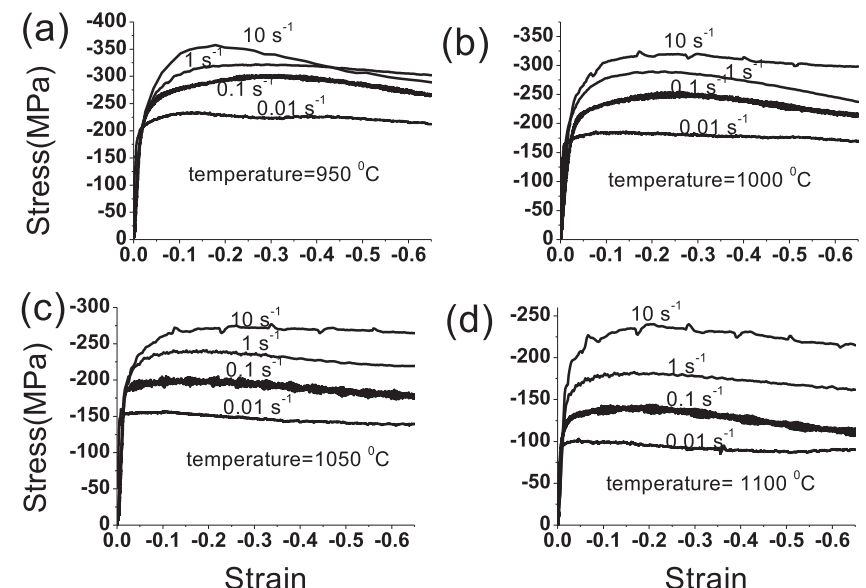

Fig. 1. True stress-strain curves at different deformation temperature (a) $\mathrm{T}=950^{\circ} \mathrm{C}$, (b) $\mathrm{T}=1000^{\circ} \mathrm{C}$, (c) $\mathrm{T}=1050^{\circ} \mathrm{C}$ and (d) $\mathrm{T}=1100^{\circ} \mathrm{C}$. $d \sigma / d \epsilon)$ as well as $d \theta / d \sigma$ decreases as stress increases. This effect is less prominent as the stress approaches peak value due to initiation of DRX at a critical value which is lower than the peak stress. The rate of decrease in $\theta(-d \theta / d \sigma)$ decelerates quickly in the region from critical stress to peak stress compared to the region prior to the initiation of DRX. This can be seen as a point of inflection in $\theta$ vs. $\sigma$ curve. At the inflection point, $-d \theta / d \sigma$ has a minimum value. After the point of inflection there is a large jump in value of $-d \theta$ / $d \sigma$ as flow stress approaches peak stress.

Jafari and Najafizadeh ${ }^{7)}$ pointed out that to find the value of strain hardening rate $\theta=d \sigma / d \epsilon$, differentiation of stressstrain curve is required. But to apply differential calculus to the curve in entire range of deformation is impossible because presence of short range noise produces large variation in values which are much larger than the mean value. To overcome such difficulties, a smooth curve is modelled by adopting a higher order polynomial curve fitting of data in the region of interest i.e. from yield to peak stress. In the current analysis $5^{\text {th }}$ order polynomial fit to true stress-strain curve from yield to the peak stress shows the best fitting as shown in Figs. 2(a) to 2(d).

$$
\sigma=A+B \varepsilon+C \varepsilon^{2}+D \varepsilon^{3}+E \varepsilon^{4}+F \varepsilon^{5}
$$

Where $A, B, C, D, E, F$ are polynomial coefficient constants.

The initiation of DRX was found at an inflection point in the $\theta$ vs. $\sigma$ curve. This point can be found by modelling the $\theta$ vs. $\sigma$ curve to a curve which contains a single minimum point. For this $3^{\text {rd }}$ order polynomial fitting curve shows single minimum point ${ }^{7}$ as described below:

$$
\begin{aligned}
& \theta=a+b \sigma+c \sigma^{2}+d \sigma^{3} \\
& \frac{d \theta}{d \sigma}=b+2 c \sigma+3 d \sigma^{2} \\
& \frac{d^{2} \theta}{d \sigma^{2}}=2 c+6 d \sigma=0 \\
& \sigma_{c r}=-c / 3 d
\end{aligned}
$$

Where $a, b, c, d$ are polynomial coefficient constants. The normalized critical stress can then be determined by dividing critical stress $\sigma_{c r}$ with the experimental peak stress $\left(\sigma_{p}\right)$.

At $1000^{\circ} \mathrm{C}$ with $10 \mathrm{~s}^{-1}, 1050^{\circ} \mathrm{C}$ with $10 \mathrm{~s}^{-1}$ the flow curve is flat (Fig. 1). Thus it shows typical dynamic recovery characteristics and falls in type (c) category. ${ }^{8)}$ However existence of an inflection point in rate of strain hardening $(\theta=$

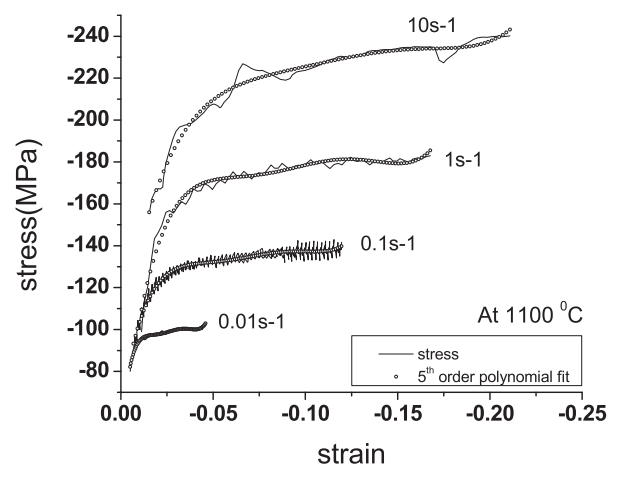

Fig. 2. $5^{\text {th }}$ order polynomial fit of the curve from yield to peak point at $1100^{\circ} \mathrm{C}$ 
$\mathrm{d} \sigma / \mathrm{d} \epsilon$ ) vs. stress $(\sigma)$ plot (Figs. 3(b) and 3(c)) and minimum point in $d \theta / d \sigma$ vs. $\sigma$ plot (Figs. 4(b) and 4(c)) signifies initiation of DRX. Microstructures shown in Figs. 7(a) and 8 (a)
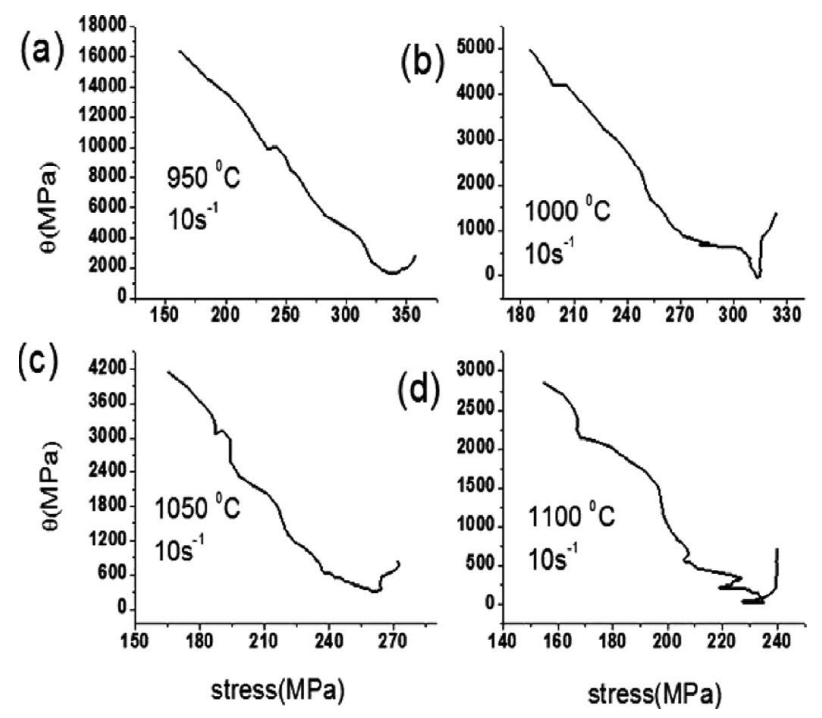

Fig. 3. Flow stress dependence of $\theta$ at $10 \mathrm{~s}^{-1}$ at (a) $950^{\circ} \mathrm{C}$, (b) $1000^{\circ} \mathrm{C}$, (c) $1050^{\circ} \mathrm{C}$ and (d) $1100^{\circ} \mathrm{C}$.
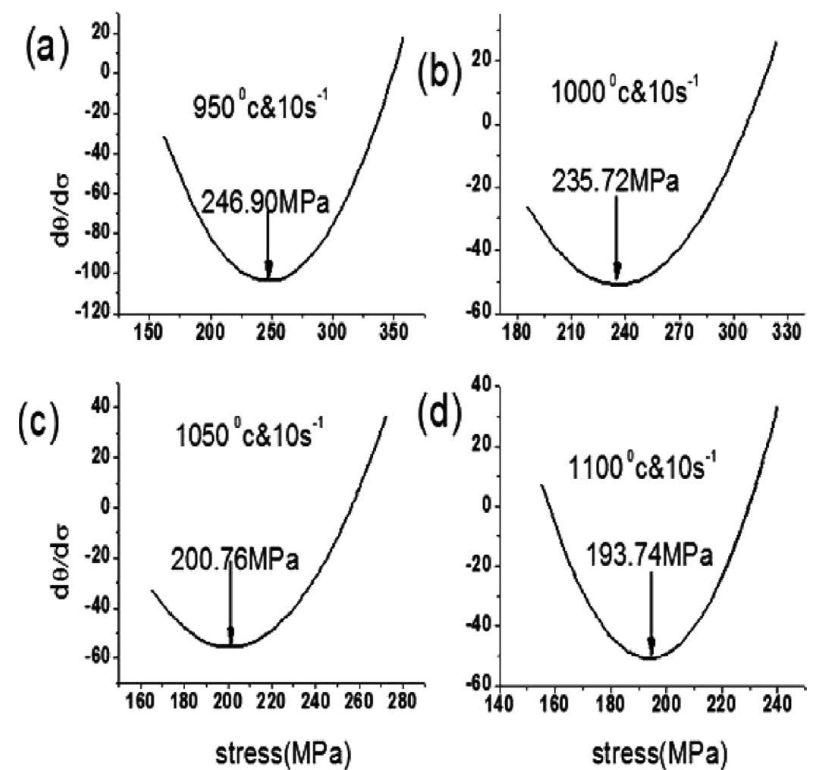

Fig. 4. Flow stress dependence of $d \theta / d \sigma$ at $10 \mathrm{~s}^{-1}$ at (a) $950^{\circ} \mathrm{C}$, (b) $1000^{\circ} \mathrm{C}$, (c) $1050^{\circ} \mathrm{C}$ and (d) $1100^{\circ} \mathrm{C}$.

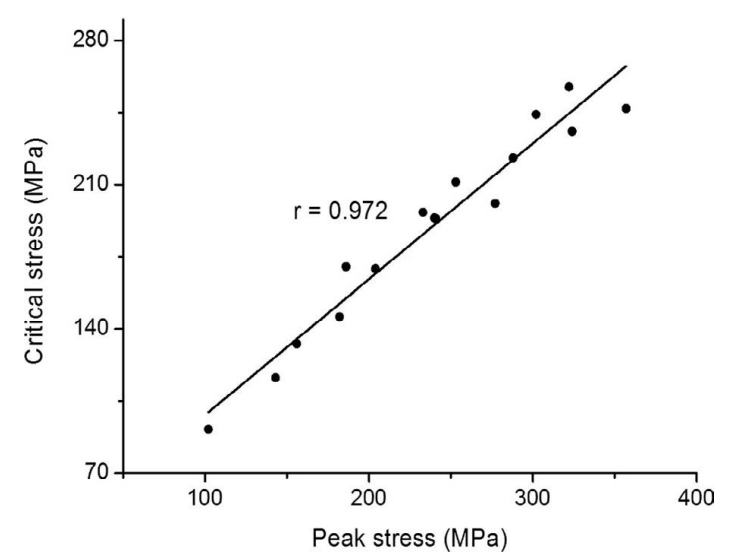

Fig. 5. Critical stress vs. peak stress. are also in agreement with initiation of DRX in these cases. Similar inflection points were observed in type (a) and type (b) cases in samples exhibiting dynamic recrystallization.

Critical stress and peak stress values were subjected to regression analysis using experimental peak stress values as independent variables and calculated critical stress values as dependent variables. Correlation coefficient (r) of the regression analysis is 0.972 as shown in Fig. 5. This reveals that critical stress and peak stress values are approximately following a linear relationship. Average normalized critical stress is found to be 0.806 which lies in the range $(0.82 \pm$ $10 \%$ ) of values specified for DRX initiation. ${ }^{8)}$

\subsection{Microstructural Analysis}

Based on the above analysis initiation of DRX in all the cases was observed at a critical stress lower than the peak stress. Microstructures of deformed samples are shown in
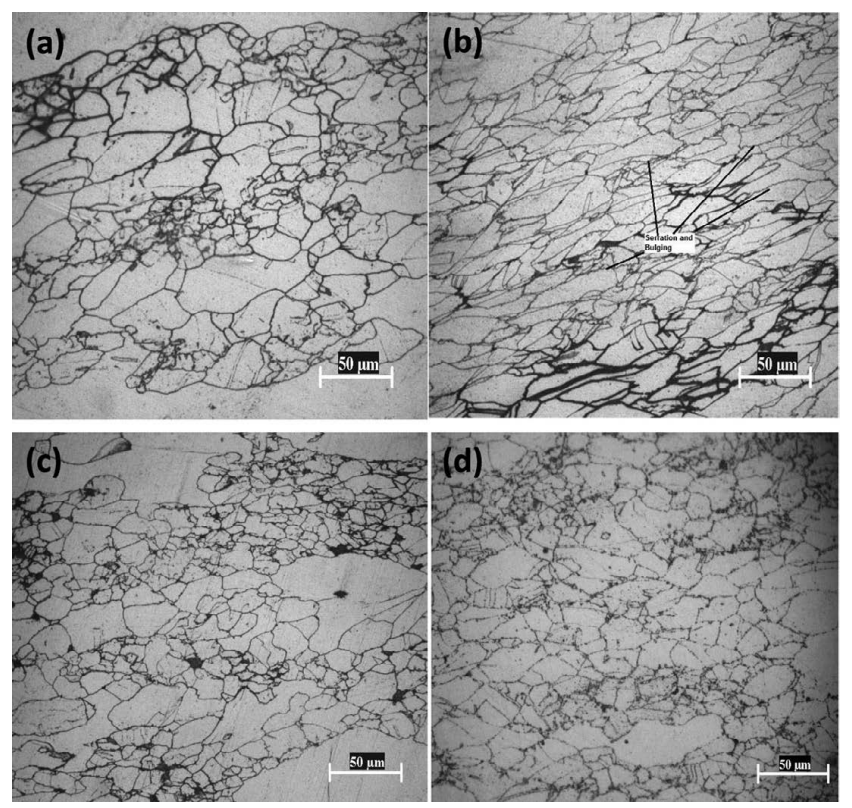

Fig. 6. Microstructure at $950^{\circ} \mathrm{C}$ with (a) $10 \mathrm{~s}^{-1}$, (b) $1 \mathrm{~s}^{-1}$, (c) $0.1 \mathrm{~s}^{-1}$ and (d) $0.01 \mathrm{~s}^{-1}$.
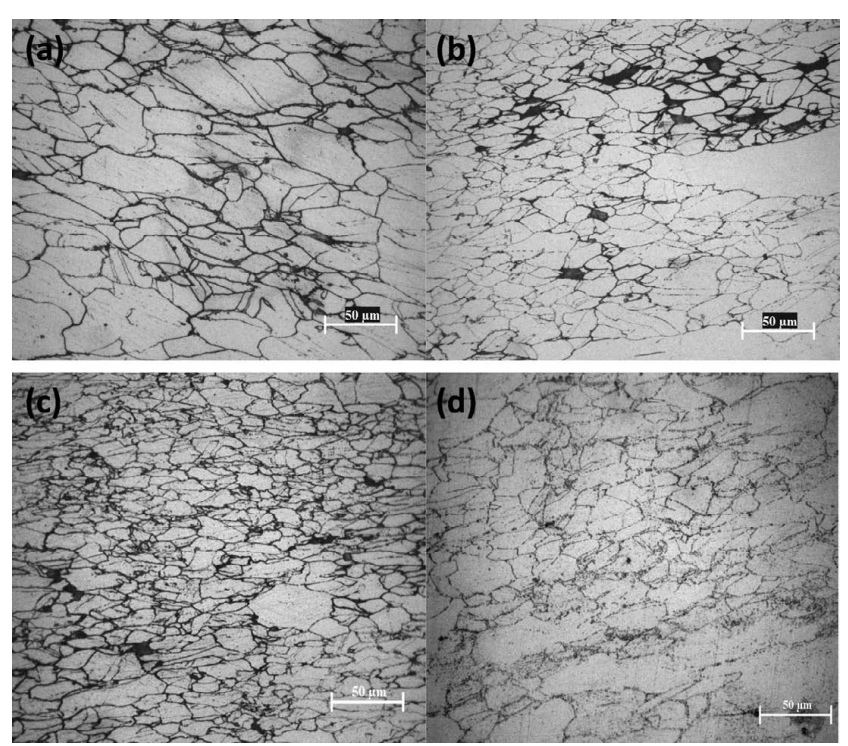

Fig. 7. Microstructure at $1000^{\circ} \mathrm{C}$ with (a) $10 \mathrm{~s}^{-1}$, (b) $1 \mathrm{~s}^{-1}$, (c) $0.1 \mathrm{~s}^{-1}$ and (d) $0.01 \mathrm{~s}^{-1}$. 

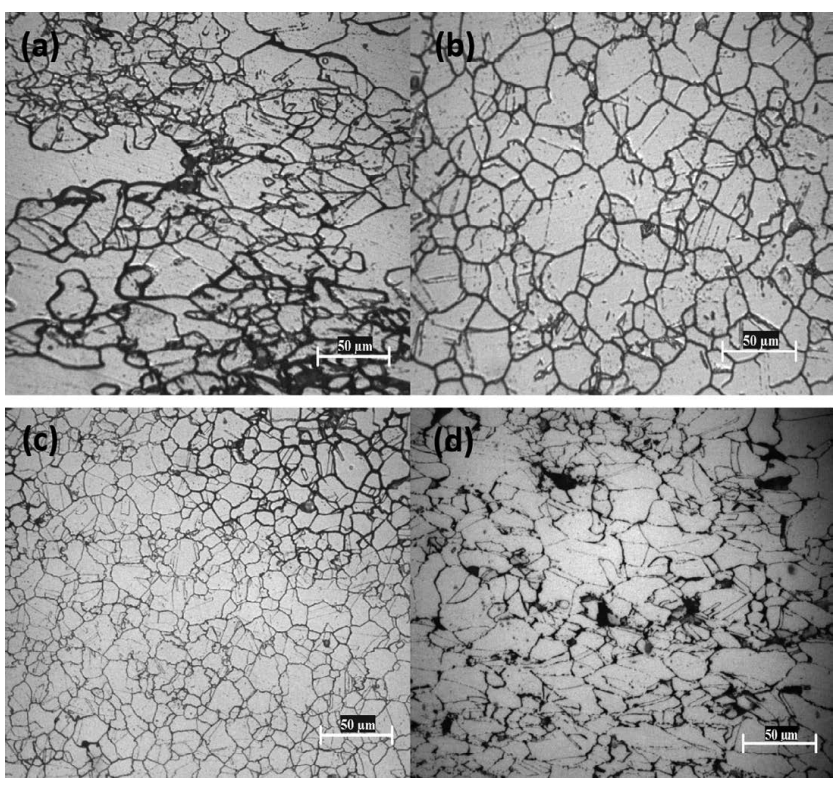

Fig. 8. Microstructure at $1050^{\circ} \mathrm{C}$ with (a) $10 \mathrm{~s}^{-1}$, (b) $1 \mathrm{~s}^{-1}$, (c) $0.1 \mathrm{~s}^{-1}$ and (d) $0.01 \mathrm{~s}^{-1}$
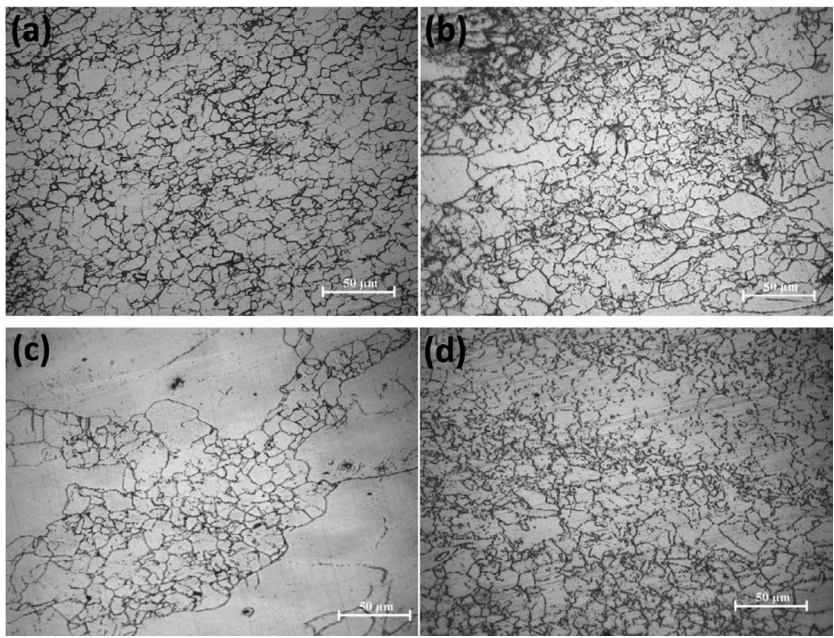

Fig. 9. Microstructure at $1100^{\circ} \mathrm{C}$ with (a) $10 \mathrm{~s}^{-1}$, (b) $1 \mathrm{~s}^{-1}$, (c) $0.1 \mathrm{~s}^{-1}$ and (d) $0.01 \mathrm{~s}^{-1}$.

Figs. 6 to 11. Carbides (expected to be $\mathrm{Cr}_{23} \mathrm{C}_{6}$ ) were observed along the grain boundaries. All microstructures obtained in the present investigation can be argued to be DRX microstructures. In all the cases a typical necklace type of microstructure (for example Fig. 10) was observed. Ponge and Gottstein reported necklace formation in $\mathrm{Ni}_{3} \mathrm{Al}{ }^{9}$ ) Jafari and Najafizadehl ${ }^{10)}$ had also reported similar necklace type structures in hot deformed microstructures of 316-austenitic stainless steel. According to their approach serration and bulging of grain boundary occurs due to grain boundary shearing accompanied by evolution of sub-grain boundaries and twins. It results in formation of a layer of new recrystallized grains along the initial grain boundary. This process of formation of new grains occurs layer by layer leaving recrystallized grains around the grain boundaries and unrecrystallized areas inside the grains. Annealing twins were observed in all the samples (e.g. Fig. 11). Presence of necklace type microstructure is an indication of incomplete DRX. Coarser DRX grains were observed at higher strain rates $\left(1 \mathrm{~s}^{-1}\right.$ and $\left.10 \mathrm{~s}^{-1}\right)$. This may be attributed to adiabatic

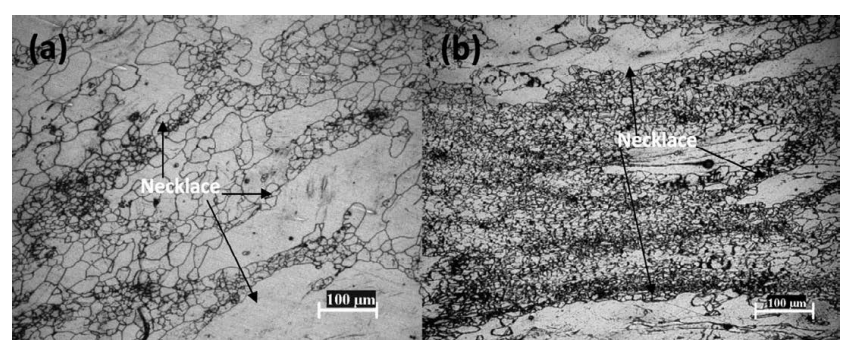

Fig. 10. Necklace microstructure at (a) $950^{\circ} \mathrm{C}$ and $10 \mathrm{~s}^{-1}$ : (b) $1100^{\circ} \mathrm{C}$ and $0.01 \mathrm{~s}^{-1}$.
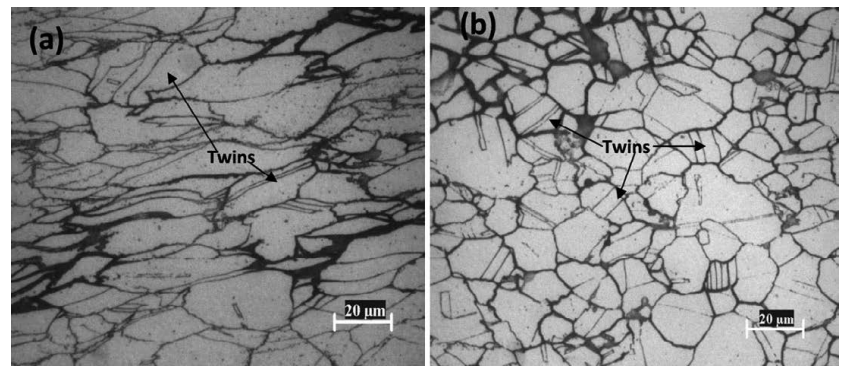

Fig. 11. Twins formation at (a) $950^{\circ} \mathrm{C}^{\text {and }} 1 \mathrm{~s}^{-1}$ : (b) $1050^{\circ} \mathrm{C}$ and $0.1 \mathrm{~s}^{-1}$.

heating at high strain rate.

\subsection{Establishment of Constitutive Equation for $23 / 8$ Steel}

The widely accepted hyperbolic sine law proposed by Sellars and McTegart ${ }^{11)}$ for all stress conditions relates the flow behaviour with deformation temperature and strain rate, and activation energy during hot deformation of the metal as follows:

$$
\varepsilon=K[\sinh (\sigma \alpha)]^{n} \exp (-Q / R T)
$$

Where $n, \alpha, \beta$ are material constants, $f(\sigma)=$ stress function, $Q=$ deformation activation energy, $T=$ Absolute deformation temperature, $K=$ Constant, $R=$ Gas constant $(8.314 \mathrm{~J}$ $\left.\mathrm{mol}^{-1} \mathrm{~K}^{-1}\right), \sigma=$ the flow stress. Flow stress in numerical analysis of high temperature deformation process may be substituted by the Peak stress, steady state stress or stress at a particular strain. But peak stress is preferably taken because it is the characteristic stress of all flow curves and steady state is not achievable in all deformed cases. ${ }^{12)}$

The synergistic effect of strain rate and temperature on flow stress is related by a single parameter $(Z)$ by ZenerHollomon $^{15)}$ as follows:

$$
Z=\varepsilon \cdot \exp (Q / R T)=f(\sigma)=K[\sinh (\sigma \alpha)]^{n}
$$

Where $Z$ is the Zener-Hollomon parameter and its physical significance is a temperature compensation of strain rate factor.

Using Eqs. (4) and (5), the constitutive equation can be expressed in terms of $\mathrm{Z}$ parameter as follows:

$$
\sigma=\left(\frac{1}{\alpha}\right) \ln \left\{\left(\frac{Z}{K}\right)^{1 / n}+\left[\left(\frac{Z}{K}\right)^{2 / n}+1\right]^{1 / 2}\right\}
$$

Taking natural logarithm of both sides of the Eq. (4)

$$
\ln \varepsilon=\ln K+n \ln \sinh (\sigma \alpha)+(-Q / R T)
$$

The hot deformation activation energy $(Q)$ and the stress 
exponent $(n)$ can be calculated as:

$$
\begin{gathered}
n=\left.\frac{\partial \ln \varepsilon}{\partial \ln [\sinh (\alpha \sigma)]}\right|_{T=\text { const. }} . . \\
Q=\left.n r \frac{\partial \ln [\sinh (\sigma \alpha)]}{\partial(1 / T)}\right|_{\mathcal{E}=\text { const. }}
\end{gathered}
$$

At constant deformation temperature slope of the plot $\ln (\sinh (\sigma \alpha)$ vs. $\ln \varepsilon$ yields $n$. Similarly from slope of the plot of $\ln \left(\sinh (\sigma \alpha)\right.$ vs. $\frac{1}{T}$ at constant strain rate, the value of $(\mathrm{Q} / R \mathrm{~T})$ can be obtained and hence $Q$ can be calculated. Linear regression method of analysis of the data was adopted for obtaining the above.

Value of stress multiplier $(\alpha)$ is unknown for the material under investigation. The optimum value of $\alpha$ has to be estimated carefully before calculating $Q$ and $n$. Its value can be selected such that the slope of $\ln (\sinh (\sigma \alpha)$ vs. $\ln \varepsilon$ at various temperatures become straight and parallel.

The range of value of $\alpha$ for steel has been reported to be 0.01 to $0.02 \mathrm{MPa}^{-1}{ }^{14)}$ Ying Han et al. ${ }^{12)}$ adopted a method to compute optimal value of $\alpha$ from that range based on the lowest standard deviation of $n$ for all the temperatures. Value of $n$ varies inversely with $\alpha$ whereas $Q$ increases or decreases to a stable value. ${ }^{14)}$ This effect was also observed in the present work (Figs. 12(a) and 12(b)). The values of $n$ have approximately similar minimum deviation for $\alpha$ value of 0.014 to $0.02 \mathrm{MPa}^{-1}$. To find the optimum value of $\alpha$, variation of activation energy with $\alpha$ was calculated by taking the average value of $n$ at particular $\alpha$ for all temperatures. The optimum value of $\alpha$ is selected at the lowest

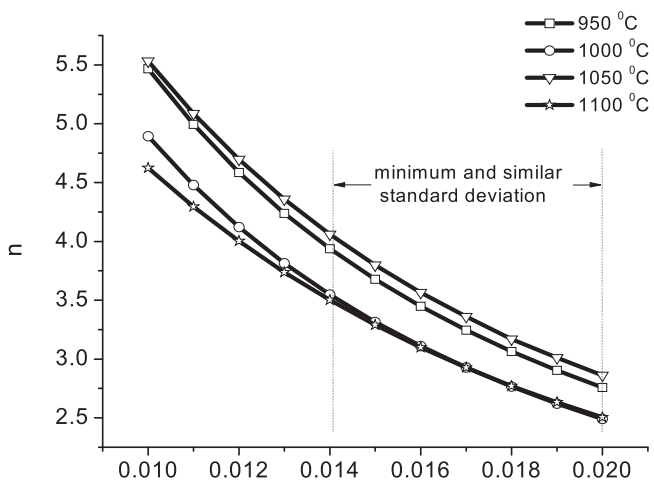

$\alpha\left(\mathrm{MPa}^{-1}\right)$

(a)

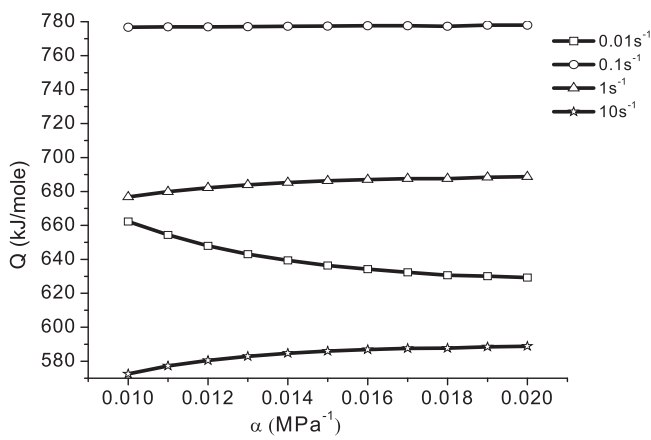

(b)

Fig. 12. (a): Variation of stress exponent (n) with $\alpha$ at different temperature and (b): Activation energy variation with $\alpha$ at different strain rate. standard deviation of activation energy. Values of activation energy range from 572 to $778 \mathrm{~kJ} /$ mole but the minimum standard deviation $(12.12 \%)$ of activation energy at all strain rates under investigation is identified at the value of $\alpha=$ $0.014 \mathrm{MPa}^{-1}$.

By averaging the slopes of the plot $\ln (\sinh (\sigma \alpha)$ vs. $\ln \varepsilon$ in Fig. 13(a), the average value of stress exponent $(n)$ is determined as 3.762. The slopes of the plot are found by following regression analysis of the data obtained at $\alpha=$ $0.014 \mathrm{MPa}^{-1}$. Similarly the average value of activation energy is found to be $671.66 \mathrm{~kJ} / \mathrm{mole}$ from the plot $\ln (\sinh (\sigma \alpha) \mathrm{vs}$. $\frac{1}{T}$ shown in Fig. 13(b).

Activation energy for self diffusion of $\gamma$-iron is reported to be $3.2 \pm 0.2 \mathrm{eV}$ which is close to $312 \mathrm{~kJ} / \mathrm{mole}^{15)}$ and is less than the value obtained in the present work. The activation energy obtained here is also larger than the values found in other types of austenite steels. ${ }^{16)}$ This may be due to a complex relationship of activation energy with alloying elements. ${ }^{21)}$ The present alloy contains significant amounts of carbon $(0.31 \mathrm{wt} \%)$ as well as high $(22.48 \mathrm{wt} \%)$ chromium and nitrogen $(0.28 \mathrm{wt} \%)$ compared to the conventional austenitic steels. Alloying can increase the value of the activation energy. ${ }^{16}$ ) This may be due to pinning effect of precipitates such as carbides on dislocations and grain boundaries raising the deformation resistance. ${ }^{17)}$ Also higher level of activation energy (up to $587 \mathrm{~kJ} / \mathrm{mole}$ ) is associated with higher nitrogen containing austenitic steels. ${ }^{18)}$ The stress exponent $(n=3.762)$ of $23 / 8$ steel is also found to be lower compared to other austenitic stainless steels $(n=4.2$

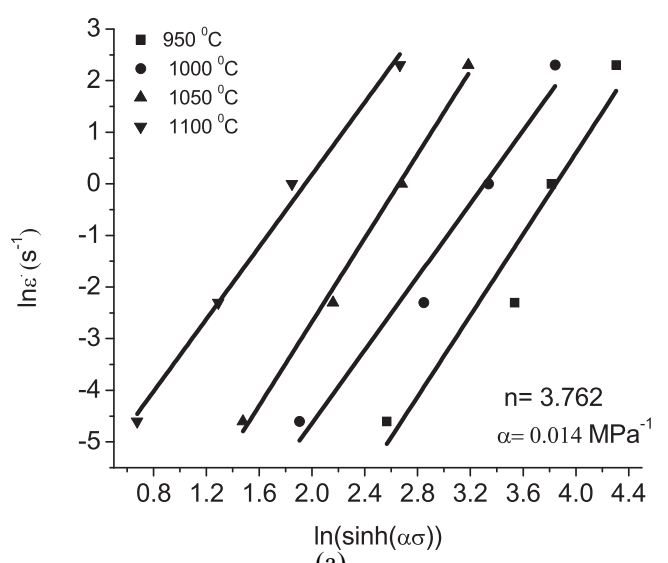

(a)

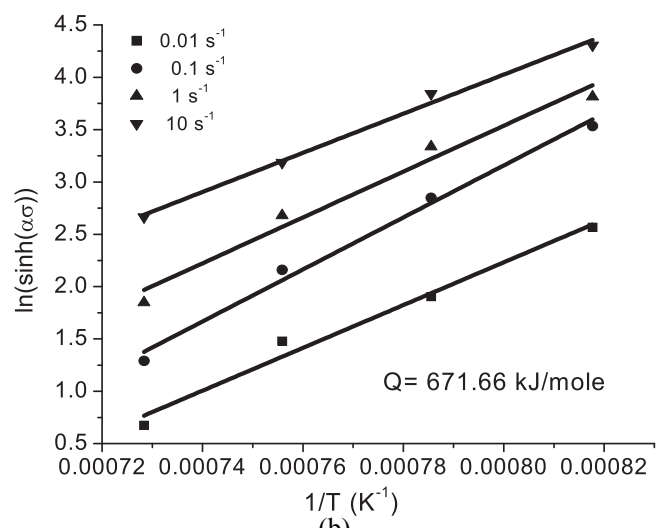

(b)

Fig. 13. (a): Relationship between hyperbolic sine function of stress with strain rate and (b): Relationship between hyperbolic sine function of stress with temperature. 
Table 2. Critical stress and normalized critical stress for DRX.

\begin{tabular}{cccc}
\hline $\begin{array}{c}\text { Deformation } \\
\text { condition }\end{array}$ & $\begin{array}{c}\text { Peak } \\
\text { stress }\left(\sigma_{p}\right)\end{array}$ & $\begin{array}{c}\text { Critical } \\
\text { stress }\left(\sigma_{c r}\right)\end{array}$ & $\begin{array}{c}\text { Normalized critical } \\
\text { stress }\left(\sigma_{p} / \sigma_{c r}\right)\end{array}$ \\
\hline $950 \& 0.01 \mathrm{~s}^{-1}$ & 233 & 196.55 & 0.843 \\
$950 \& 0.1 \mathrm{~s}^{-1}$ & 302 & 244 & 0.807 \\
$950 \& 1 \mathrm{~s}^{-1}$ & 322 & 257.43 & 0.799 \\
$950 \& 10 \mathrm{~s}^{-1}$ & 357 & 246.90 & 0.691 \\
$1000 \& 0.01 \mathrm{~s}^{-1}$ & 186 & 170.08 & 0.914 \\
$1000 \& 0.1 \mathrm{~s}^{-1}$ & 253 & 211.14 & 0.834 \\
$1000 \& 1 \mathrm{~s}^{-1}$ & 288 & 222.93 & 0.774 \\
$1000 \& 10 \mathrm{~s}^{-1}$ & 324 & 235.72 & 0.727 \\
$1050 \& 0.01 \mathrm{~s}^{-1}$ & 156 & 132.75 & 0.85 \\
$1050 \& 0.1 \mathrm{~s}^{-1}$ & 204 & 169.12 & 0.829 \\
$1050 \& 1 \mathrm{~s}^{-1}$ & 241 & 193.34 & 0.802 \\
$1050 \& 10 \mathrm{~s}^{-1}$ & 277 & 200.76 & 0.724 \\
$1100 \& 0.01 \mathrm{~s}^{-1}$ & 102 & 91.19 & 0.894 \\
$1100 \& 0.1 \mathrm{~s}^{-1}$ & 143 & 116.35 & 0.813 \\
$1100 \& 1 \mathrm{~s}^{-1}$ & 182 & 145.85 & 0.801 \\
$1100 \& 10 \mathrm{~s}^{-1}$ & 240 & 193.74 & 0.807
\end{tabular}

Table 3. $\mathrm{Z}$ parameter and calculated and experimental values of peak stress.

\begin{tabular}{ccccc}
\hline $\begin{array}{c}\text { Deformation } \\
\text { condition }\end{array}$ & $\begin{array}{c}\text { Zener-Hollomon } \\
\text { parameter }(\mathrm{Z})\end{array}$ & $\begin{array}{c}\text { Experimental } \\
\text { Peak stress } \\
\left(\sigma_{p}\right)\end{array}$ & $\begin{array}{c}\text { Calculated } \\
\text { peak stress } \\
\left(\sigma_{c}\right)\end{array}$ & $\begin{array}{c}\text { \% error } \\
\text { in peak } \\
\text { stress }\end{array}$ \\
\hline $950 \& 0.01 \mathrm{~s}^{-1}$ & $4.8731 \times 10^{26}$ & 233 & 240.68 & 3.29 \\
$950 \& 0.1 \mathrm{~s}^{-1}$ & $4.8731 \times 10^{27}$ & 302 & 284.33 & 5.85 \\
$950 \& 1 \mathrm{~s}^{-1}$ & $4.8731 \times 10^{28}$ & 322 & 328.04 & 1.87 \\
$950 \& 10 \mathrm{~s}^{-1}$ & $4.8731 \times 10^{29}$ & 357 & 371.75 & 4.13 \\
$1000 \& 0.01 \mathrm{~s}^{-1}$ & $3.6393 \times 10^{25}$ & 186 & 191.66 & 3.04 \\
$1000 \& 0.1 \mathrm{~s}^{-1}$ & $3.6393 \times 10^{26}$ & 253 & 235.15 & 7.05 \\
$1000 \& 1 \mathrm{~s}^{-1}$ & $3.6393 \times 10^{27}$ & 288 & 278.80 & 3.19 \\
$1000 \& 10 \mathrm{~s}^{-1}$ & $3.6393 \times 10^{28}$ & 324 & 322.49 & 0.46 \\
$1050 \& 0.01 \mathrm{~s}^{-1}$ & $3.3068 \times 10^{24}$ & 156 & 146.97 & 5.78 \\
$1050 \& 0.1 \mathrm{~s}^{-1}$ & $3.3068 \times 10^{25}$ & 204 & 189.86 & 6.93 \\
$1050 \& 1 \mathrm{~s}^{-1}$ & $3.3068 \times 10^{26}$ & 241 & 233.33 & 3.18 \\
$1050 \& 10 \mathrm{~s}^{-1}$ & $3.3068 \times 10^{27}$ & 277 & 276.98 & 0.007 \\
$1100 \& 0.01 \mathrm{~s}^{-1}$ & $3.5782 \times 10^{23}$ & 102 & 107.2 & 5.09 \\
$1100 \& 0.1 \mathrm{~s}^{-1}$ & $3.5782 \times 10^{24}$ & 143 & 148.42 & 3.79 \\
$1100 \& 1 \mathrm{~s}^{-1}$ & $3.5782 \times 10^{25}$ & 182 & 191.34 & 5.13 \\
$1100 \& 10 \mathrm{~s}^{-1}$ & $3.5782 \times 10^{26}$ & 240 & 234.83 & 2.15 \\
\hline
\end{tabular}

to 4.6). This may be attributed to the presence of alloying elements or precipitates which may decrease the $n$ value. ${ }^{14,16)}$

Value of $Z$ can be calculated from Eq. (5) using the value of $Q$ determined above. Calculated values of $Z$ are listed in Table 3. Taking natural logarithm of both sides of the equation, Eq. (5) can be expressed as:

$$
\ln Z=\ln K+n \ln (\sinh (\sigma \alpha)
$$

From plot of $\ln Z$ vs. $\ln (\sinh (\sigma \alpha)$ value of the constant $K$ can be found from intercept $(\ln K)$ of the regression line (Fig. 14). The value of $K$ is determined as $2.075 \times 10^{22}$.

Substituting values of material constants $(\alpha, n$ and $K)$ and average activation energy for processing in Eq. (4), the hot

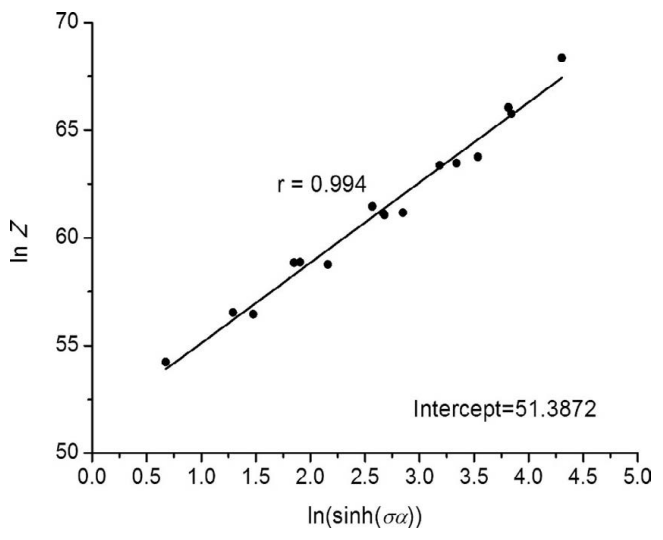

Fig. 14. Relation between Zener-Hollomon parameter and stress.

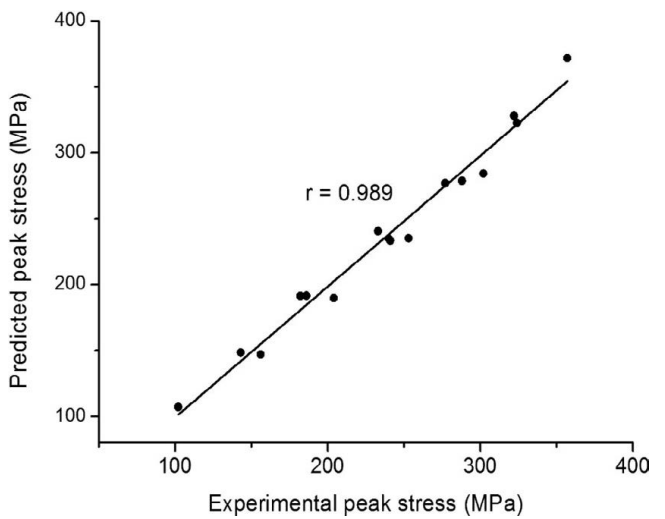

Fig. 15. Comparison between experimental and predicted peak stress.

deformation equation for $23 / 8$ steel can be established as: $\mathcal{E}=2.075 \times 10^{22}[\sinh (0.014 \sigma)]^{3.762} \exp (-671660 / R T)$

The prediction of peak stress embracing Zener-Hollomon parameter is

$$
\begin{aligned}
& \sigma=\left(\frac{1}{0.014}\right) \\
& \ln \left\{\left(\frac{Z}{2.075 \times 10^{22}}\right)^{1 / 3.762}+\left[\left(\frac{Z}{2.075 \times 10^{22}}\right)^{2 / 3.762}+1\right]^{1 / 2}\right\} \ldots \\
& Z=\varepsilon \exp (671660 / R T)=K[\sinh (0.014 \sigma)]^{3.762} \ldots . .
\end{aligned}
$$

The Z-parameter can be related to grain growth and grain size distribution in the final microstructure. ${ }^{19)}$ In the present work high value of $Z$ is obtained at higher strain rates and low temperatures. At high $Z$ values the delayed initiation of DRX results in high work hardening. As the work hardening reaches a critical value a large amount of DRX grains will nucleate. This correlates with the microstructure shown in Figs. 6 to 9 and the calculated $Z$-parameter from Table 3. At low $Z$ values inhomogeneous grain size distribution occurred and small grains are mixed with some large grains. It has been reported ${ }^{19)}$ that at low $Z$ value the recrystallized grains formed initially grow rapidly and the concurrent work hardening is unable to restrict their growth. Thus some recrystallized grains grow quickly inhibiting the adjacent grains to grow. 


\subsubsection{Verification of the Constitutive Model}

The deviation of the predicted result from the experimental result was quantified by standard statistical parameters namely correlation coefficient ( $\mathrm{r}$ ) and absolute average relative error (AARE) using the formulas ${ }^{20)}$ as given below:

$$
\begin{gathered}
r=\frac{\sum_{i=1}^{N}\left(e_{i}-\bar{e}\right)\left(p_{i}-\bar{p}\right)}{\sqrt{\sum_{i=1}^{N}\left(e_{i}-\bar{e}\right)^{2} \sum_{i=1}^{N}\left(p_{i}-\bar{p}\right)^{2}}} \\
A A R E=\frac{1}{N} \sum_{i=1}^{N}\left|\frac{\left(e_{i}-p_{i}\right)}{e_{i}}\right| \times 100
\end{gathered}
$$

Where $e_{i}=$ experimental finding, $p_{i}=$ calculated value from the predicted equation, $\bar{e}=$ average of experimental value and $\bar{p}=$ average of predicted value.

The correlation coefficient (r) and absolute average relative error were calculated to be 0.989 and $3.808 \%$ respectively. Thus the proposed mathematical equation for prediction of flow stress of $23 / 8$ steel fits well with the experimental data. Variation between results calculated from predicted equation and experimental values may be due to flow softening caused by adiabatic heating, flow instability, wedge cracking etc. which were not taken into account while developing this model.

\subsection{Investigation of Hot Workability by Development of Processing Map}

The concept of dynamic material model (DMM) is the basis of development of processing maps. According to this the metal under hot working dissipates power $(P)$ through two forms: $G$ (dissipater content) responsible for temperature rise during plastic flow and $\mathrm{J}$ (dissipater co-content) responsible for Microstructural changes. ${ }^{21,22)}$ Mathematically it can be written as:

$$
P=G+J \quad \text { or } \quad \sigma \varepsilon^{\cdot}=\int_{0}^{\varepsilon} \sigma d \varepsilon^{\cdot}+\int_{0}^{\sigma} \varepsilon d \sigma
$$

The power partitioning between these two complementary parts is controlled by Strain rate sensitivity $(m)$ parameter. ${ }^{21,22)}$

From Eq. (16), it follows that the rate of change of $J$ with respect to $G$ at a given temperature and strain estimates strain rate sensitivity $(m)$ :

$$
m=\left(\frac{\partial J}{\partial G}\right)_{\varepsilon, T}=\left(\frac{\varepsilon \cdot \partial \sigma}{\sigma \partial \varepsilon}\right)_{\varepsilon, T}=\left[\frac{\partial(\ln \sigma)}{\partial(\ln \varepsilon)}\right]_{\varepsilon, T}
$$

Prasad et al. ${ }^{21,22)}$ considered that the flow stress obeys power law $\left(\sigma=K \varepsilon^{. m}\right)$ and formulated the power dissipation efficiency in terms of $\mathrm{m}$ as below:

$$
G=\frac{P}{1+m}, \quad J=\frac{m P}{1+m}
$$

Under the two extreme conditions of $m$ such as $m=1$ and $m=0$ the material behaviour can be explained as: For ideal plastic flow stress, $m=1$, the flow stress is proportional to strain rate at any temperature and strain. In this condition the value of J turns, $J_{\max }=P / 2$ and maximum power dissipation occurs. For $m \rightarrow 0$, the value of $G$ approaches $P$ and $J$ approaches zero in which all the power dissipates by heat. This is a condition of plastic instability.
The power dissipation efficiency can be defined as:

$$
\eta_{1}=\frac{J}{J_{\max }}=\frac{2 J}{P}=\frac{2 m}{1+m}
$$

Prasad et $a l .^{21)}$ outlined the instability criteria based on Ziegler's continuum principles ${ }^{23}$ applied to large plastic deformation as:

$$
\xi_{1}=\frac{\partial \ln [m / 1+m]}{\partial \ln \varepsilon}+m \leq 0
$$

Murty and $\mathrm{RaO}^{24,25)}$ considered that the dynamic response does not always obey the power law and $m$ varies with temperature and strain rate. They proposed a modified DMM which is applicable to all conditions (whether power law is obeyed or not). According to them power dissipation efficiency can be calculated as follows:

$$
\eta_{2}=\frac{J}{J_{\max }}=\frac{2 J}{P}=\frac{2 \times(P-G)}{P}=2 \times(1-G / P)_{T, \varepsilon}
$$

The value of $G, J$ can be calculated from Eq. (16) as given below:

$$
J=P-G=\sigma \varepsilon-\int_{0}^{\varepsilon} \sigma d \varepsilon
$$

The integration in Eq. (22) requires the experimental data at $\varepsilon=0$. To avoid this difficulty the integral is split as:

$$
\int_{0}^{\varepsilon_{\min }} \sigma d \varepsilon+\int_{\varepsilon_{\min }}^{\varepsilon} \sigma d \varepsilon^{\cdot}=\left[\frac{\sigma d \varepsilon}{1+m}\right]_{\varepsilon^{\prime}=\varepsilon_{\min }}+\int_{\varepsilon_{\min }}^{\varepsilon} \sigma d \varepsilon
$$

Where $\varepsilon_{\min }$ is the minimum value of experimental strain rate $\left(0.01 \mathrm{~s}^{-1}\right.$ here $)$ and the value of $\mathrm{m}$ can be obtained from the derivative of $\ln \sigma$ vs. $\ln \varepsilon$ curve fitted with $3^{\text {rd }}$ order polynomial. The integral in Eq. (23) can be calculated using the trapezoidal rule. ${ }^{2)}$

Based on Ziegler's criterion, the instability parameter $(\xi)$ outlined by Murty and $\operatorname{Rao}^{24,25)}$ for any type of $\sigma-\varepsilon$ curve as:

$$
\xi_{2}=2 \frac{m}{\eta}-1=\frac{m P}{J}-1<0
$$

Figures 16(a), 16(b), 16(c) shows the variation of $J / P, G /$ $P, m$ with strain rate respectively while Fig. 16(d) shows the variation of $\mathrm{m}$ with $J / G$ for true strain of 0.6 at $\mathrm{T}=950$ $1100^{\circ} \mathrm{C}$. From Figs. $16(\mathrm{a}), 16(\mathrm{~b})$ it can be predicted that a huge part $(>80 \%)$ of the power is involved in plastic flow $(G)$. In the deformation condition of 0.6 strain with $950^{\circ} \mathrm{C}$ and $10 \mathrm{~s}^{-1}$ the value of $G / P$ more than unity and $J / P$ less than zero indicates the occurrence of plastic instability due to adiabatic shearing at low processing temperature and high strain rate. ${ }^{2)}$ From Figs. 16(a) and 16(c) it can also be noted that the value of $J / P$ at any strain rate need not be negative if $m$ is negative because $\mathrm{m}$ accounts for local information (negative $\mathrm{m}$ implies local instability) whereas $J$ gives the global information at any strain rate. ${ }^{25)}$ Figure $16(\mathrm{f})$ shows the comparison between the power dissipation efficiency $\left(\eta_{2}\right)$ obtained using method of Murty et al. with that of Prasad et al. at 0.6 strain. From Figs. 16(d) and 16(f) it can be seen that all the points do not lie on the line $J / G=m$ and $\eta_{2}=$ $2 m /(m+1)$. Further the flow stress vs $\ln \varepsilon$ plots in Fig. 16(e) deviate from linear relationship. The above plots indicate that flow stress does not obey the power law in all the deformation conditions during the present research. Thus 


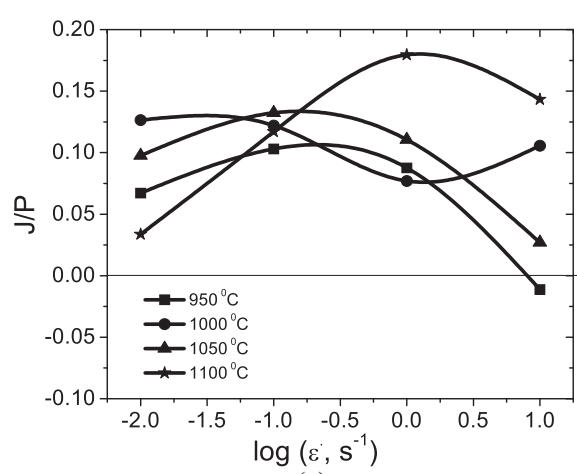

(a)

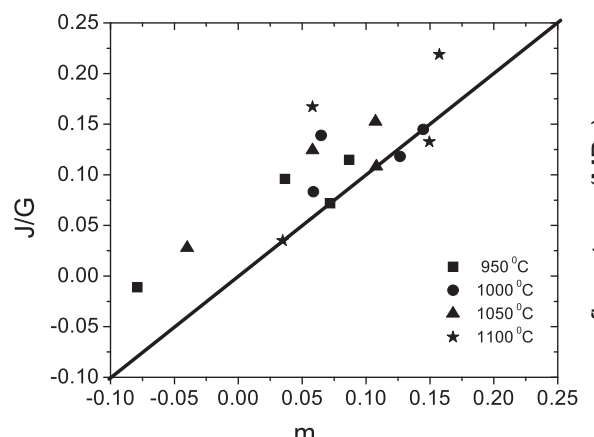

(d)

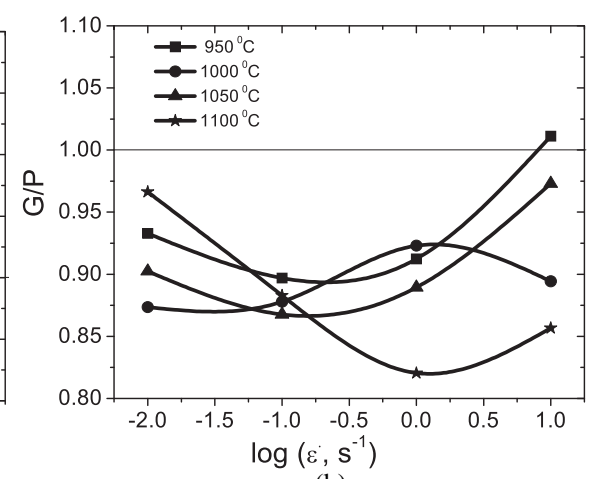

(b)

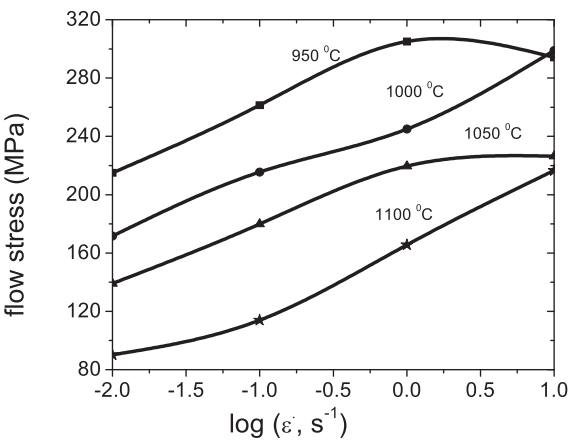

(e)

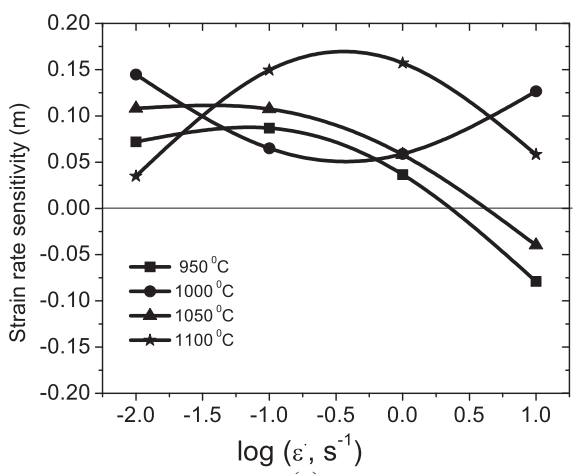

(c)

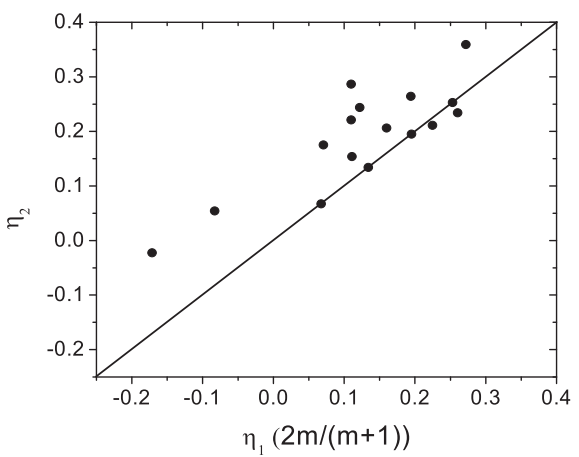

(f)

Fig. 16. (a): dependence of $J / P$ with strain rate at different temperature, (b): dependence of $G / P$ with strain rate at different temperature, (c): dependence of $m$ with strain rate at different temperature, (d): variation of strain rate sensitivity with $J / G$ at different temperature, (e): variation of flow stress with strain rate at different temperature and (f): comparison of power dissipation efficiency by Murty and Prasad at 0.6 strain.

the modified DMM has been used for further analysis.

The power dissipation efficiency and instability criteria were determined by modified DMM method presented by Murty (using Eqs. (21) to (24)). The power dissipation efficiency map was superimposed on the instability map to obtain processing map. Figure 17 presents the processing maps at 0.6 strain with stable regions marked as shaded and hatched. The contours in the map are represented as the constant efficiency of power dissipation in percentage.

From Fig. 17 it is observed that most of the regions except few are having negative value of instability parameter and come under unstable domain. The stable processing conditions are:

$$
\begin{aligned}
& * 950-1100^{\circ} \mathrm{C}, 0.01 \mathrm{~s}^{-1} \\
& * 1000^{\circ} \mathrm{C}, 10 \mathrm{~s}^{-1} \\
& * 1100^{\circ} \mathrm{C}, 0.1 \mathrm{~s}^{-1}
\end{aligned}
$$

Except these above conditions all other conditions should be avoided during the hot working of the $23 / 8$ steel.

The peak efficiency of $35.91 \%$ at 0.6 strain was observed in the material under $1100^{\circ} \mathrm{C}$ and $1 \mathrm{~s}^{-1}$. The values of the peak efficiency obtained here are in good agreement with the power dissipation efficiency (max. 30-40\%) for dynamic recrystallization in low stacking faulty energy materials such as austenitic stainless steels $(304,304 \mathrm{~L}, 904,316$, 316LN etc.). ${ }^{3,12,26-30)}$ Based on the observed peak efficiency value, microstructure and the flow softening nature of flow curves (in Fig. 1), it can be argued that highest amount of dynamic recrystallization may be occurring in the peak efficiency domain mentioned above.

Higher efficiency corresponds to the more energy involved in microstructural change and results in dynamic recrystallized grains which is beneficial to the hot deforma-

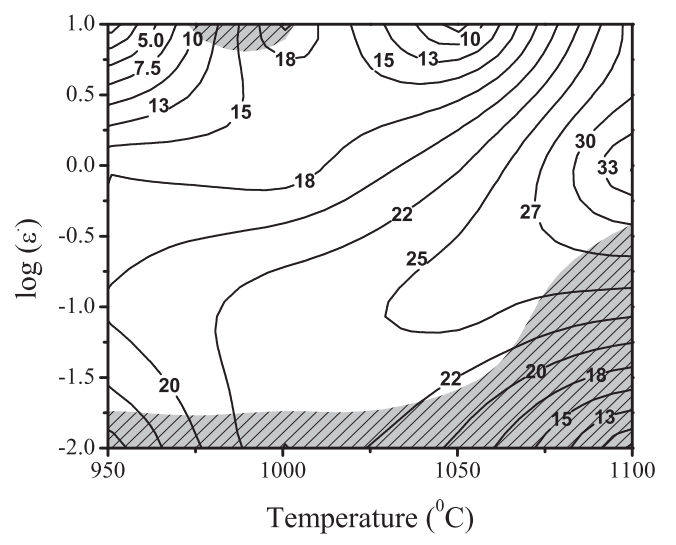

Fig. 17. Processing maps at 0.6 strain rate using modified DMM method. The shaded regions are the stable regions for thermomechanical processing.

tion process. The optimum processing condition can be identified as the value of highest efficiency in the stable or safe processing zone. For strain value of 0.6 the peak efficiency of $35.91 \%$ is found under the processing condition of $1100^{\circ} \mathrm{C}, 1 \mathrm{~s}^{-1}$. But the negative value of instability criteria obtained under this condition predicts unstable microstructure (Fig. 17). So to avoid instability in microstructure, the optimum processing condition should be $1100^{\circ} \mathrm{C}, 0.1 \mathrm{~s}^{-1}$ having efficiency of $23.4 \%$. This falls in the stable (shaded) region of the processing map (Fig. 17).

During hot deformation process super plasticity, wedge cracking, dynamic recrystallization, dynamic recovery, void formation, flow localisation cracking, intercrystalline cracking and adiabatic shear band formation may occur. Out of this super plasticity, dynamic recrystallization and dynamic recov- 
ery are the safe processes during high temperature deformation and rest are the damage mechanisms. In addition, damage mechanisms such as twin formation and necklace formation also contribute to microstructural instability. ${ }^{27,28,30)}$

Typical necklace type of microstructure was observed in this material. The wider necklaces in the microstructure were observed in the conditions having lower dissipation efficiency. Also a large no of annealing twins were observed in the microstructures having negative instability criteria. Presence of twins and necklace type of microstructure may contribute to the microstructure instability in the $23 / 8$ steel. The efficiency of power dissipation is not so high (more than $60 \%$ ) to cause super plasticity and wedge cracking in the present research. ${ }^{31)}$ Though cracks may present at low temperature and high strain rate, no cracks were observed in the present work. Thus dominating damage mechanisms causing microstructure instability in this material may be twin formation and necklace microstructure.

\section{Conclusions}

The high temperature deformation behaviour of $23 / 8$ steel in the range of temperature $950-1100^{\circ} \mathrm{C}$ and strain rate $0.01-10 \mathrm{~s}^{-1}$ was investigated using Gleeble 3800 thermomechanical simulator.

(1) The average deformation activation energy $(Q)$ and stress exponent $(n)$ are $671.66 \mathrm{~kJ} / \mathrm{mole}$ and 3.762 respectively. The established deformation equation for $23 / 8$ steel may be written as:

$$
\varepsilon=2.075 \times 10^{22}[\sinh (0.014 \sigma)]^{3.762} \exp (-671660 / R T)
$$

(2) Prediction of peak stress embracing Zener-Hollomon parameter is :

$$
\begin{aligned}
& \sigma=\left(\frac{1}{0.014}\right) \\
& \ln \left\{\left(\frac{Z}{2.075 \times 10^{22}}\right)^{1 / 3.762}+\left[\left(\frac{Z}{2.075 \times 10^{22}}\right)^{2 / 3.762}+1\right]^{1 / 2}\right\}
\end{aligned}
$$

(3) Dynamic recrystallization with necklace type of microstructure is observed in the range of temperature 950$1100^{\circ} \mathrm{C}$ and strain rate $0.01-10 \mathrm{~s}^{-1}$.

(4) The average normalized critical stress for dynamic recrystallization is 0.806 .

(5) The peak efficiency of $35.91 \%$ at 0.6 strain was observed under $1100^{\circ} \mathrm{C}$ and $1 \mathrm{~s}^{-1}$ whereas the optimum processing condition was found under $1100^{\circ} \mathrm{C}$ and $0.1 \mathrm{~s}^{-1}$ having efficiency of $23.4 \%$.

(6) Dominating damage mechanisms causing microstructure instability in this material may be twin formation and necklace microstructure.

The predicted values of peak stress obtained using the above equations agree well with those obtained experimentally. The value of the activation energy obtained in the present work is higher than those reported for conventional austenitic steels. Further the stress exponent obtained was also lower than those reported.

\section{Acknowledgements}

The authors are grateful to M/S Star Wire (India) Ltd., Ballabhgarh (Haryana) for supply of the materials.

\section{REFERENCES}

1) V. G. Gavriljuk: ISIJ Int., 36 (1996), 738.

2) S. V. S. N. Murty and B. N. Rao: J. Phy., D 31 (1998), 3306.

3) S. Venugopal and P. V. Sivaprasad: J. Mater. Eng. Perf., 12 (2003), 674.

4) Z. Wang, W. Fu, S. Sun, H. Li, Z. Lv and D. Zhao: Metall. Mater. Trans. A, 41 (2010), 1025

5) M. El. Wahabi, J. M. Cabrera and J. M. Prado, Mater. Sci. Eng. A, 343 (2003), 116.

6) E. I. Poliak and J. J. Jonas: Acta Mater., 44 (1996), 127

7) M. Jafari and A. Najafizadeh: J. Mater. Sci. Technol., 24 (2008), 840.

8) G. Gottstein and U. F. Kocks: Acta Metall., 31 (1983), 175.

9) D. Ponge and G. Gottstein: Acta Mater., 46 (1998), 69.

10) M. Jafari and A. Najafizadeh: Mater. Sci. Eng. A, 501 (2009), 16.

11) C. M. Sellars and W. J. McTegart: Acta Metall., 14 (1996), 1136.

12) Y. Han, G. Liu, D. Zou, R. Liu and G. Qiao: Mater. Sci. Eng. A, 565 (2013), 342.

13) J. H. Hollomon and C. Zener: J. Appl. Phys., 15 (1944), 22.

14) A. M. Jorge, Jr., M. M. Peres, C. S. Kiminami, C. Bolfarini and W. J. Botta: Metall. Mater. Trans. A, 40 (2009), 3322.

15) F. S. Buffington, K. Hirano and M. Cohen: Acta Metall., 9 (1961), 434.

16) H. J. McQueen, J. Yue, N. D. Ryan and E. Fry: Mater. Process. Technol., 53 (1995), 293.

17) J. C. Shao, B. I. Xiao, Q. Z. Wang, Z. Y. Ma, Y. Liu and K. Yang: Mater. Sci. Eng. A, 527 (2010), 7865.

18) E. S. Silva, R. C. Sousa, Jr., A. M. Jorge and O. Balancin: Mater. Sci. Eng. A, 534 (2012), 69.

19) A. D. Manshadi, M. R. Barnett and P. D. Hodson: Metall. Mater. Trans. A, 39A (2008), 1359.

20) Y. Han, G. Qiao, J. Sun and D. A. Zou: Compt. Mater. Sci., 67 (2013), 93.

21) Y. V. R. K. Prasad: Ind. J. Tech., 28 (1990), 435.

22) Y. V. R. K. Prasad: J. Mater. Eng. Perf., 12 (2003), 638.

23) H. Ziegler: Pro. Sol. Mech., 4 (1963), 93.

24) S. V. S. N. Murty, B. N. Rao and B. P. Kashyap: Mod. Simu. Mater. Sci. Eng., 10 (2002), 503.

25) S. V. S. N. Murty and B. N. Rao: J. Mater. Sci. Lett., 18 (1999), 1757.

26) S. Venugopal, S. L. Mannan and Y. V. R. K. Prasad: Mater. Lett., 17 (1993), 388.

27) S. Venugopal, S. L. Mannan and Y. V. R. K. Prasad: Scr. Mater., 28 (1993), 715.

28) Y. V. R. K. Prasad and N. Ravichandran: Bull. Mater. Sci., 14 (1999), 1241.

29) P. Fajfar, B. Bradaskja, B. Pirnar and M. Fazarinc: RMZ - Materials and Geoenvironment, 58 (2011), 383.

30) B. Er, W. Mingjia, W. Zixi and W. Huan: Mater. Sci. Forum, 704705 (2012), 210

31) R. Raj: Metall. Trans. A, 12 (1981), 1089. 